\title{
Phytochemical Studies and In Vitro Evaluation of Antioxidant \& Antihyperglycemic Activities of Actinidia deliciosa (A. Chev.) C.F. Liang \& A.R. Ferguson (Kiwifruit)
}

\author{
Vivek Kumar Dhiman, Vivek Chauhan, and Shamsher Singh Kanwar*
}

Department of Biotechnology, Himachal Pradesh University, India

*Corresponding author: Shamsher Singh Kanwar, Department of Biotechnology, Himachal Pradesh University, India, Tel: +91 8219994569; Email: kanwarss2000@yahoo.com

Received: 09 Jan, 2020 | Accepted: 25 Mar, 2020 | Published: 31 Mar, 2020

Citation: Dhiman VK, Chauhan V, Kanwar SS (2020) Phytochemical Studies and In Vitro Evaluation of Antioxidant \& Antihyperglycemic Activities of Actinidia deliciosa (A. Chev.) C.F. Liang \& A.R. Ferguson (Kiwifruit). J Biochem Analyt Stud 4(1): dx.doi.org/10.16966/2576-5833.119

Copyright: (c) 2020 Dhiman VK, et al. This is an open-access article distributed under the terms of the Creative Commons Attribution License, which permits unrestricted use, distribution, and reproduction in any medium, provided the original author and source are credited.

\begin{abstract}
The fruit of Actinidia deliciosa (A. Chev.) C.F. Liang \& A.R. Ferguson, kiwifruit also known as 'China's miracle fruit' and 'Horticulture wonder of New Zealand' is a very well-known fruit with excellent bioactive properties associated with good health attributes such as healthful skin, better sleep contributed by antioxidants and serotonin content of kiwifruit. It also maintains cardiovascular health and blood pressure as kiwifruit is a good source of potassium, fibre and antioxidants. Antioxidant properties help in anti aging and blood cleansing activities while antihyperglycemic compounds may lead to antidiabetic effects. The purpose of the present study was to investigate the biochemical constituents of the kiwifruit and to establish its antioxidant and antihyperglycemic effects. The chemical profiling of kiwi fruit extracts in two solvents (Ethanol and Methanol) indicated the presence of steroids, cardiac glycosides, terpenoids, flavonoids and carbohydrates. Antioxidant capacity was performed using 1,1-diphenyl-2picrylhydrazyl (DPPH) radical inhibition whereas, $\alpha$-amylase inhibitory assay was performed using $\alpha$-amylase from Aspergillus oryzae. Methanolic extracts of kiwifruit (Actinidia deliciosa) possessed highest inhibitory activities out of the two extracts (compared to ethanolic extracts) against DPPH free radical and $\alpha$-amylase. $I_{50}$ (concentration of extract which results in $50 \%$ inhibition) values were calculated for both Methanol (MKE) and Ethanol Extract (EKE) of kiwifruit. IC ${ }_{50}$ values for $\mathrm{DPPH}$ free radical scavenging assay was $4.2 \pm 0.073 \mathrm{mg} / \mathrm{mL}$ for $\mathrm{MKE}$ and for $3.14 \pm 0.153 \mathrm{mg} /$ $\mathrm{mL}$ fir EKE. On other hand, the alpha-amylase assay IC $\mathrm{I}_{50}$ value was found to be $1.53 \pm 0.158 \mathrm{mg} / \mathrm{mL}$ for $\mathrm{MKE}$ and $2.05 \pm 0.639 \mathrm{mg} / \mathrm{mL}$ for EKE. Kinetic analysis revealed that the EKE and MKE displayed competitive mode of inhibition toward $\alpha$-amylase. In the study, kiwifruit proved to have health beneficial effects as both antioxidant and antihyperglycemic properties were found in its extract.
\end{abstract}

Keywords: Actinidia deliciosa Chev.cv. Abbot; DPPH; $\alpha$-amylase; IC ${ }_{50}$ value; Phyto-chemical screening; Antioxidant capacity; Antihyperglycemic

\section{Introduction}

Kiwifruit is a worldwide known fruit among the genus Actinidia (Actinidiaceae). It is a dioecious plant, widely distributed in Asia. It is native to China but most of the species are cultivated in the southwest part of China. Today kiwifruit is cultivated in many countries, notably Italy, New Zealand, China, Chile, France, Greece, Japan and United States. Kiwifruit consists of various phyto-constituents belonging to category of steroid, triterpenoids, flavonoids, quinones, polysaccharides and phenylpropanoids such as $\beta$-sitosterol, stigmastane sterols, asiatic acid, arjunolic acid, 9'-cis-violaxanthin, pheophytin b, pheophytin $\mathrm{q}$, lutein epoxide, pyrrolo quinoline quinone, rhamnose, arabinose, xylose, glucose, mannose and phytoalexins [1-3]. The fruits, seeds, stems and roots naturally possess diuretic, natural blood thinner, febrifuge and sedative properties [4]. It has been reported to be beneficial in the treatment of diseases like rheumatoid arthritis, hepatitis, edema, gingivitis, pyorrhea, etc. Studies have reported kiwifruit to possess immunomodulatory and anticancerous activities [5,6]. A study performed in Norway revealed that consuming 2-3 kiwifruit daily for 28 days can replace aspirin therapy and can significantly thin the blood. Thus, it can help in reducing the risk of clots and in lowering the fats in the blood which are prominent causes of blockages [7].

According to many studies, the intake of kiwifruit plant products caused reduced risk of chronic diseases that have been associated with the compounds possessing antioxidant activities [8]. Carotenoids and Vitamin E contributes to the first defence system against oxidative stress by quenching singlet oxygen [9]. These antioxidants act together and reduce free radicals or reactive oxygen species which are harmful to the living system [10]. Furthermore, the methanolic extracts of kiwifruit showed regulation of adipogenesis in adipocyte differentiation and function which is important in prevention of diabetes [11]. Keeping in view an array of medicinal benefits of kiwifruit, the present study was performed to check the phytoconstituents present in the fruit. However, some of phyto-constituents such as cardiac glycosides have not been quantified in previous 
studies and the antidiabetic potency of Actinidia deliciosa Chev. and its mechanism of inhibition have not been extensively studied till now. Therefore, the antioxidant and alpha amylase-inhibitory activities of the Actinidia deliciosa Chev. Crude fruit extracts were determined to establish its health promoting nature.

\section{Materials and Methods}

\section{Plant material}

The fruits of Actinidia deliciosa Chev. cv. Abbot were obtained from Kiwifruit Orchard ( $\left.30^{\circ} .51 .44 \mathrm{~N} ; 77^{\circ} .09 .32 \mathrm{E} ; 1290 \mathrm{amsl}\right)$, Department of Fruit Science, Dr. Y. S. Parmar University of Horticulture \& Forestry, Nauni-Solan (India) in the month of October 2019. All the samples were washed properly and stored under chilling conditions $\left(0^{\circ} \mathrm{C}\right.$ temperature).

\section{Chemicals and reagents}

DPPH and alpha-amylase from Aspergillus oryzae were procured from Sigma-Aldrich Co., St. Louis, USA, while starch soluble (analytical grade) was obtained from HiMedia Laboratories Pvt. Ltd., Mumbai, India. Other chemicals and reagents were of analytical grade and water used was glass distilled.

\section{Preparation of kiwifruit extract}

Actinidia deliciosa Chev. Whole kiwifruits were washed with water to remove all the contaminants followed by surface cleansing with $70 \%$ ethanol. The fruits were weighed and grinded into fine particles by using blender. Then this slurry ( $14 \mathrm{~g}$ each) was soaked in $350 \mathrm{ml}$ of selected solvent (70\% ethanol and $70 \%$ methanol) separately in 1:25 (w/v) ratio. Soaking of all samples was done for $48 \mathrm{~h}$ under dark condition. Both slurries (Ethanolic kiwifruit extract: EKE; Methanolic kiwifruit extract: MKE) were kept under constant shaking (200 rpm) for 48 hours at $30^{\circ} \mathrm{C}$. Then, the contents of the mixtures were filtered through a muslin cloth and finally through Whatman No.1 filter paper. The extraction solvents were evaporated at $30^{\circ} \mathrm{C}$ under reduced pressure in a rotatory vacuum evaporator until sample was solvent free. The dried residues were weighed and their stock solution were made in distilled water. The yield (percentage) was calculated using the following equation:

Yield $(\%)=($ initial weight of extract in $\mathrm{g} /$ final weight of concentrated extract in $\mathrm{g}) \times 100$.

The alcoholic extracts were stored in a refrigerator for assay of antioxidant activity and for phytochemical analysis.

\section{Preliminary phytochemical screening of kiwifruit extracts (EKE and MKE)}

Phytochemical composition of the A. deliciosa Chev. Ancoholic fruit extracts were determined using different methods. Extracts (EKE and MKE) were treated with few drops of $2 \%(\mathrm{w} / \mathrm{v})$ ferric chloride solution. Formation of blue-black colouration indicated the presence of phenols [12]. A few drops of Molisch's reagent was added into fruit extracts followed by concentrated sulphuric acid slowly along the walls of the test tube. A reddish violet ring showed the presence of carbohydrate in the test sample [13]. Extracts were treated with1.0 $\mathrm{ml}$ of chloroform followed by a few drops of concentrated sulphuric acid along the sides of test tube. A reddish-brown colouration at the interphase indicated the presence of terpenoids [14]. Extracts were treated with a few drops of acetic anhydride, shaken and added with $1.0 \mathrm{ml}$ of concentrated sulphuric acid, a colour change from violet to blue green indicated the presence of steroids $[15,16]$. Extracts were treated with $1.0 \mathrm{ml}$ of glacial acetic acid, mixed well, added a few drops of 5 percent ethanolic ferric chloride solution, shaken, slowly and added $1.0 \mathrm{ml}$ of concentrated sulphuric acid. An appearance of a brownish ring between the two layers with lower acidic layer turning blue-green upon standing indicated the presence of cardiac glycosides $[17,18]$. Extracts were treated with $1.0 \mathrm{ml}$ of Wagner's reagent, mixed well, added $1 \%(\mathrm{v} / \mathrm{v})$ hydrochloric acid. The reaction mixtures were incubated in hot water bath for 5 minutes. Appearance of precipitate in the reaction mixture indicated the presence of alkaloids [19]. Extracts were also treated with $1.0 \mathrm{ml}$ of $10 \%(\mathrm{w} / \mathrm{v})$ sodium hydroxide solution. The yellow colouration which appeared later turned colorless upon addition of dilute acid indicated the presence of flavonoids [20].

\section{Quantitative determination of phytochemical constituents of kiwifruit extracts (EKE and MKE)}

Determination of total flavonoid content: The total flavonoid contents of A. Deliciosa Chev. Crude fruit extracts were measured using a colorimetric assay developed by Stankovic MS, et al. [21]. A known volume $(1.0 \mathrm{ml})$ of extract (EKE and MKE) was added to a 10 $\mathrm{ml}$ volumetric flask followed by addition of $0.15 \mathrm{ml}$ of $5 \%(\mathrm{w} / \mathrm{v})$ sodium nitrite $_{2}$. After $5 \mathrm{~min}, 2 \%(\mathrm{w} / \mathrm{v})$ of $0.15 \mathrm{ml}$ aluminium chloride was added. Further, after $6 \mathrm{~min}$, the reaction mixture was neutralized with $1.0 \mathrm{ml}$ of $1 \mathrm{M} \mathrm{NaOH}$ solution and total volume was made up to $10 \mathrm{ml}$ with distilled water, mixed well and monitored spectrophotometrically at $510 \mathrm{~nm}$. The flavonoid content was expressed as micrograms of quercetin equivalents per milligram of fresh material.

Quantitative estimation of steroids: The amounts of total steroids in A. Deliciosa Chev. Crude fruit extracts were determined according to the procedure reported by Patra A, et al. [22]. Each of kiwi extracts (1.0 ml, EKE and MKE) was transferred into $10 \mathrm{ml}$ volumetric flask followed by addition of $2.0 \mathrm{ml}$ of $4 \mathrm{~N}$ sulphuric acid and $2.0 \mathrm{ml}, 0.5 \%$ $(\mathrm{w} / \mathrm{v})$ iron (III) chloride. Added $0.5 \mathrm{~mL}$ of $0.5 \%(\mathrm{w} / \mathrm{v})$ potassium hexacyanoferrate (III) solution into the reaction mixture. Heated the reaction mixture in a water-bath set at $70 \pm 2^{\circ} \mathrm{C}$ for 30 minutes with constant shaking and the content was diluted with deionised water. Absorption at $780 \mathrm{~nm}$ was measured against a reagent blank. The steroid content was determined in kiwifruit extract using cycloartenol as a standard. Total steroid content was expressed as micrograms of cycloartenol equivalents per milligram of fresh material.

Quantitative test for cardiac glycosides: The total cardiac glycoside contents of A. Deliciosa Chev. Crude fruit extracts were measured using a colorimetric assay developed by Muhammad SA, et al. [23]. Eight millilitres of kiwifruit extract (EKE and MKE) was transferred to a $100 \mathrm{ml}$ volumetric flask followed by addition of $60 \mathrm{ml}$ of deionised water and $18 \mathrm{ml}$ of $12.5 \%(\mathrm{w} / \mathrm{v})$ lead acetate, the content was mixed well and filtered. Then, $50 \mathrm{ml}$ of filtrate were transferred into another $100 \mathrm{ml}$ flask and $8 \mathrm{ml}$ of $47 \%(\mathrm{w} / \mathrm{v})$ disodium monophosphate was added to precipitate excess $\mathrm{Pb}^{2+}$ ion. The contents were mixed well and completed the final volume with deionised water. The mixture was filtered twice through same filter paper to remove excess lead phosphate. The $10 \mathrm{ml}$ of filtrate transferred into a clean Erylen-Meyer flask was treated with $10 \mathrm{ml}$ of Baljet reagent. A blank titration was carried out using $10 \mathrm{ml}$ of distilled water and $10 \mathrm{ml}$ of Baljet reagent. This mixture was allowed to stand for one hour for complete colour development. The colour intensity was measured colorimetrically at $495 \mathrm{~nm}$ using the following equation:

TotalGlyü $\quad i d e=\frac{A_{\mathrm{u}} \times \ddot{\mathrm{u}} g}{77}$

Quantitative estimation of carbohydrates by Phenol-sulphuric acid method: The total carbohydrate contents of alcoholic A. Deliciosa 
Chev. Crude fruit extracts were determine using a modified method of Nielsen [24]. Aliquot of kiwifruit extracts (2.0 ml, EKE and MKE) were added into two sets of test tubes containing $5 \%(\mathrm{w} / \mathrm{v})$ phenol $(2.0 \mathrm{ml})$, the contents were mixed well, to which slowly added $5 \mathrm{ml}$ of concentrated sulphuric acid and vortexed the contents. The reaction mixture was allowed to stand for 10 minutes followed by incubation of $10 \mathrm{~min}$ at $25^{\circ} \mathrm{C}$. Vortexed the mixture again and measured the absorbance at $490 \mathrm{~nm}$. The total carbohydrate content determined in extract using glucose as a reference compound was expressed as micrograms of glucose equivalents per milligram of fresh material.

\section{Antioxidant assay}

Free radical-scavenging activity: The DPPH (1,1-diphenyl-2picrylhydrazyl) radical scavenging capacity of $A$. Deliciosa Chev. crude fruit extracts were measured according to the method of Rajurkar NS, et al. [25].The stock solution $(100 \mathrm{mM})$ of DPPH $(4 \mathrm{mg} / 10 \mathrm{ml})$ was diluted to the ratio of 1:10. Aliquots $(0.5 \mathrm{ml})$ of DPPH stock were added into different test tubes followed by increasing concentrations $(10-100 \mathrm{mg} / \mathrm{ml})$ of kiwifruit extract. Deionised water was added to make the final volumeto $1.0 \mathrm{ml}$. incubated the content for $30 \mathrm{~min}$. The absorbance was measured at $517 \mathrm{~nm}\left(\mathrm{~A}_{517}\right)$ against a reagent blank on a UV-Visible spectrophotometer. The radical scavenging activity was measured as a decrease in the absorbance of DPPH in the presence of test sample/compound. The DPPH radical scavenging capacity was estimated from the difference in absorbance for the sample and blank, expressed in terms of percentage of DPPH scavenging. The extent of discoloration of the violet colour of DPPH radical, as it gets reduced, indicated the radical scavenging potential of the antioxidant [26]. The reaction mixture was vortexed vigorously followed by incubation period of $1 \mathrm{~h}$ in a hot-water bath at $37^{\circ} \mathrm{C}$, after which the $\mathrm{A}_{517}$ of the reaction mixture was recorded. The absorbance decreased due to colour change from purple to yellow as a result of radical scavenged by the antioxidant through the donation of hydrogen to form the stable DPPH molecules. Quercetin was used as a reference molecule for calibration of a reference profile.

Scavenging (\%) of kiwifruit extract $=\left(\mathrm{C}_{\mathrm{Abs}}-\mathrm{S}_{\mathrm{Abs}}\right) / \mathrm{C}_{\mathrm{Abs}} \times 100$

Where $\mathrm{C}=\mathrm{A}_{517}$ of Control and $\mathrm{S}=\mathrm{A}_{517}$ of test sample.

The $\mathrm{IC}_{50}$ (concentration of extract resulting in $50 \%$ reduction of the DPPH radical) values were calculated using a linear regression analysis which indicated antioxidant capacity of kiwifruit extract(s).

Alpha-amylase inhibitory assay: In vitro alpha-amylase inhibition assay was performed according to the method of McCue PP, et al. [27]. A total of $200 \mu \mathrm{l}$ of A. Deliciosa Chev. Crude fruit extracts (20$100 \mathrm{mg} / \mathrm{ml}$ ) was taken in a test-tube followed by addition of $200 \mu \mathrm{l}$ of alpha-amylase solution $(0.5 \mathrm{mg} / \mathrm{ml})$ prepared in $20 \mathrm{mM}$ sodium phosphate buffer ( $\mathrm{pH}$ 6.9). The contents were pre incubated at $25^{\circ} \mathrm{C}$ for $15 \mathrm{~min}$, after which $200 \mu \mathrm{l}$ of $1 \%(\mathrm{w} / \mathrm{v})$ starch solution prepared in $2 \mathrm{mM}$ sodium phosphate buffer ( $\mathrm{pH}$ 6.9) was added. The mixture was further incubated at $25^{\circ} \mathrm{C}$ for $10 \mathrm{~min}$. To the reaction mixture $500 \mu \mathrm{l}$ of dinitro salicylic acid (DNS) reagent was added to stop the reaction and then incubated the test-tube in hot boiling water for $5 \mathrm{~min}$ followed by cooling at room temperature. The control was prepared in distilled water instead of fruit extract using the above procedure. The reaction mixtures were finally diluted using $5 \mathrm{ml}$ of distilled water and $\mathrm{A}_{540}$ values were recorded. The alpha-amylase inhibitory activity was calculated as:

$$
\text { PercentageInhibition }=\left(\frac{\text { Control }_{540}-\text { Extract }_{540}}{\text { Control }_{540}}\right) \times 100
$$

The $\mathrm{IC}_{50}$ (concentration of extracts resulting in $50 \%$ inhibition of enzyme activity) values were calculated using a linear regression analysis that indicated the inhibitory potential of kiwifruit extracts.

Calculation of $\mathrm{IC}_{50}$ : The $\mathrm{IC}_{50}$ for each sample were calculated according to the following procedure:

The inhibition ratio (y) and sample concentration ( $\mathrm{x}$ ) were plotted against each other. Respective regression line was drawn to obtain a regression equation $(y=\mathrm{mx}+\mathrm{c})$. The sample concentration $(\mathrm{x})$ was calculated at $\mathrm{y}=50$ in the regression equation. This calculated value was set as the $\mathrm{IC}_{50}(\mathrm{mg} / \mathrm{ml})$ value of each analytical sample.

Mode of a-amylase inhibition: A. Deliciosa Chev. Crude fruit extracts (EKE and MKE) were used for kinetic study of $\alpha$-amylase inhibition according to the modified method by Ali $\mathrm{H}$, et al. [28]. A total of $250 \mu \mathrm{l}$ of kiwifruit extract was pre-incubated with $250 \mu \mathrm{l}$ of alpha-amylase solution $(0.5 \mathrm{mg} / \mathrm{ml})$ in $20 \mathrm{mM}$ phosphate buffer ( $\mathrm{pH} \mathrm{6.9)} \mathrm{for} 10 \mathrm{~min}$ at $25^{\circ} \mathrm{C}$ in a set of tubes. In another set of tubes $250 \mu \mathrm{l} \alpha$-amylase was pre-incubated. To the reaction mixtures $250 \mu \mathrm{l}$ of starch solution was added to both sets of reaction mixtures at increasing concentrations $(0.30,0.90,1.50,2.50$ and $5.0 \mathrm{mg} / \mathrm{ml})$ to start the reaction. The reaction mixtures incubated for $10 \mathrm{~min}$ at $25^{\circ} \mathrm{C}$ were boiled for $5 \mathrm{~min}$ after the addition of $500 \mu \mathrm{l}$ of DNS. The amount of reducing sugars released in each case was determined spectrophotometrically at $\mathrm{A}_{540}$ using a maltose standard curve and converted to reaction velocities as follows:

Activity $(\mathrm{U}=\mathrm{mmoles} / \mathrm{min} / \mathrm{mL})=\mathrm{S}_{\mathrm{Abs}}-\mathrm{B}_{\mathrm{Abs}} / \mathrm{Std}_{\mathrm{Abs}}-\mathrm{B}_{\mathrm{Abs}} \times$ Conc. ${ }_{\text {std }} /$ Incubation time $\mathrm{X} \mathrm{n} / \mathrm{MW}_{\text {maltose' }}$;

where $\mathrm{S}=$ Sample, $\mathrm{B}=\mathrm{Buffer}$, Std=Standard, Conc.=Concentration, $\mathrm{n}=$ Dilution factor and $\mathrm{MW}=$ Molecular weight.

A double reciprocal plot $\left(1 / V^{\circ}\right.$ versus $\left.1 /[S]\right)$ where $V$ is reaction velocity and $[S]$ is substrate concentration was plotted. The type or mode of inhibition and kinetic parameters of the A. Deliciosa Chev. Fruit extracts on $\alpha$-amylase activity was determined by analysis of the double reciprocal (Lineweaver-Burk) plot using Michaelis-Menten kinetics. Kinetic parameters were calculated by adjusting curves to the Lineweaver-Burk kinetic equation:

$$
1 / V=\left(K_{\mathrm{m}} / \mathrm{V}_{\max }\right)(1 / S)+1 / \mathrm{V}_{\max }
$$

Starch-agar gel diffusion test: Starch-agar plates (containing $0.5 \%$ of soluble starch with $2.5 \%$ of agar) were prepared [29]. Five holes were punched in the agar medium of the plate followed by addition of $30 \mu \mathrm{l}$ of each of the reaction mixtures containing increasing concentrations of EKE and MKE $(60,80$ and $100 \mathrm{mg} / \mathrm{ml})$ treated $\alpha$-amylase; a positive control containing alpha $a$-amylase in sodium phosphate buffer $(0.5 \mathrm{mg} / \mathrm{ml})$ and a negative control containing only buffer. Plates were incubated overnight for diffusion to happen at $20^{\circ} \mathrm{C}$, followed by detection and measurement of starch hydrolysed zones using iodine solution.

\section{Statistical analysis}

Statistical analysis was performed using Microsoft excel. All the results were expressed as Mean \pm SE for triplicate determinations. Values of $\mathrm{p} \leq 0.05$ which were considered as significant.

\section{Results and Discussion}

\section{Fruit material preparation and yield of the extract}

To investigate the efficiency of solvents in extraction of specific components, the yields of each of the specified biochemical constituents of $A$. Deliciosa Chev. Fruit extracts was determined. The 
A. Deliciosa Chev. Fruit extracts gave yield in EKE (3.47 g) and MKE (1.66 g) extract of 24.83 and $11.8 \%$, respectively. Yang H, et al. [30] reported $7.9 \%$ and $8.6 \%$ yield $(\mathrm{w} / \mathrm{w})$ of ethanol extracts whereas 4.1 and 13.0 yield (w/w) of solvent fractions (Ethyl acetate and $n$-Butanol) from Actinidia deliciosa and Actinidiachinensis fruit peel, respectively. Prior investigations assessed the impact of different types of solvents on extraction of bioactive compounds from various plant parts, such as fruits, leaves and seeds [31]. Interestingly, the extraction procedure attempted in the present study appeared to be quite efficient than the earlier investigations. The variation in extracted residue(s) amount and yield was mostly dependent on use of good solvent with lesser toxicity, quick mass transfer, lower boiling point and preservative action. Furthermore, other essential factors which determined the efficiency of extraction procedure were the type of extract, temperature and the extraction time involved [32].

\section{Qualitative analysis}

Primary phytochemical investigation: In a preliminary approach, Actinidia deliciosa Chev. Crude fruit extracts were employed for preliminary phytochemical screening of various secondary metabolites by reported chemical assays (Table 1). The phytochemical analysis of both alcoholic extracts revealed excellent presence of steroids, cardiac glycosides, terpenoids, flavonoids and carbohydrates. Several studies have been conducted on kiwifruit, in order to determine their bioactive compounds [33-38]. EKE and MKE extracts gave positive results for the presence of most of the phytoconstituents.

\section{Quantitative analysis}

Total flavonoid content: Flavonoids are most important among plant secondary metabolites with miscellaneous bioactive, antioxidant effects and are considered indispensable in its pharmaceutical, medicinal, nutraceutical and cosmetics applications [39]. The amount of flavonoids in the A. Deliciosa Chev. Fruit extracts were measured by the development of flavonoid-aluminium-complex during the reaction between sodium nitrite and aluminium chloride. Total Flavonoid Contents (TFC) in EKE and MKE were calculated using quercetin analytical curve $(10-100 \mu \mathrm{g} / \mathrm{ml})$ based on the UV-Vis signal $\left(\mathrm{Y}=0.007 \mathrm{x}+0.159 ; \mathrm{R}^{2}=0.982\right)$. The determination of the TFC of EKE and MKE extracts $(100 \mathrm{mg} / \mathrm{ml})$, expressed as quercetin equivalents $(\mu \mathrm{g} / \mathrm{mg})$, established flavonoid abundance in methanolic extract (0.37) than that of ethanolic extract (0.28). Fiorentino A, et al. [38] quantified TFC in A. Deliciosa cv. Hayward crude extracts. Their analysis reported massive amounts of flavonoids in polar extracts (catechin equivalent; 131.7 to $108.9 \mathrm{mg} / 100 \mathrm{~g}$ of fruit weight) whereas non-polar extract showed limited or no results. TFC (catechin

Table 1: Qualitative phytochemical analysis of Actinidia deliciosa.

\begin{tabular}{|l|l|c|c|}
\hline Phytochemicals & \multicolumn{1}{|c|}{ Chemical test } & $\begin{array}{c}\text { Methanolic } \\
\text { extract }\end{array}$ & $\begin{array}{c}\text { Ethanolic } \\
\text { extract }\end{array}$ \\
\hline Flavonoids & Sodium hydroxide test & + & + \\
\hline Terpenoids & Salkowaski test & ++ & + \\
\hline Steroids & $\begin{array}{l}\text { Lieberman Burchard's } \\
\text { test }\end{array}$ & ++ & ++ \\
\hline Carbohydrates & Molisch's test & ++ & ++ \\
\hline Cardiac glycosides & Keller-Killani test & + & + \\
\hline Tannins & Ferric Chloride test & - & - \\
\hline Alkaloids & Wagner's test & - & - \\
\hline
\end{tabular}

+ Indicated presence of phytochemicals

++ Indicated excellent presence of phytochemicals

- Indicated absence of phytochemicals equivalent; $\mathrm{mg} / 100 \mathrm{~g}$ of fruit weight) of $A$. kolomikta (69.05), A. arguta (188.43) and A. chinensis (67.63) were established using an aluminium colorimetric assay which showed three Actinidia extracts in decreasing order A. arguta $>$ A. kolomikta $>$ A. chinensis [40]. Flavonoids identified during mass spectrometric studies of $A$. Deliciosa fruit extracts characterized 11 flavonoid molecules as naringenin, quercetin, tricin,3-O- $\alpha$-L-rhamopyranosyl derivatives of flavones kaempferol and quercetin, quercetin-3-O- $\beta$-D-glucopyranoside, kaempferol-3-O$\beta$ rutinoside,rutin, epicatechin, catechin and gallocatechin [38].

Total steroid content: Steroids are cholesterol derived, lipophilic, low-molecular weight compounds which are used in many food additives, cosmetics and as ingredient in formulation of various medicines or drugs [41]. The phytosterols in the A. Deliciosa Chev. Fruit extract reacts with the ferric chloride and potassium hexacyanoferrate in the presence of concentrated sulphuric acid to give a pink-red coloured complex whose intensity is directly proportional to the amount of steroids present. Total Steroid Content (TSC) in EKE and MKE $(100 \mathrm{mg} / \mathrm{ml})$ were calculated using cycloartenol analytical curve $(4-28 \mu \mathrm{g} / \mathrm{ml})$ based on the UV-Vis signal $(\mathrm{Y}=0.0029 \mathrm{x}+0.107$; $\left.\mathrm{R}^{2}=0.9989\right)$. The determination of the TSC of EKE and MKE extracts $(100 \mathrm{mg} / \mathrm{ml})$, expressed as cycloartenol equivalents $(\mu \mathrm{g} /$ $\mathrm{mg}$ ), established higher steroid content (13.50) in ethanol extract compared to methanolic extract (12.58). However, limited studies have been done to estimate total steroid content of Actinidia fruits. Fiorentino A, et al. [38] characterized 7 types of phytosterols in $A$. deliciosa 'Hayward' organic fruit extracts identified as stigmasterol, $\beta$-sitosterol, campesterol, stigmast-7-en-3 $\beta$-ol, ergosterol, its peroxide derivative and 5,7,14,22-ergostatetraen-3 $\beta$-ol via GCMS analysis. These phytosterols contributes in reduction of the hematic cholesterol level and as a chemo preventive agent to inhibit carcinogenesis processes.

Total cardiac glycoside content: Cardiac glycosides are one of several classes of drugs or medicines used in treating myocardial infarction, certain irregular heartbeats and various heart related conditions [42]. Kiwifruit is enriched with glycosides and its total cardiac glycoside content was estimated in EKE and MKE (100 mg/ $\mathrm{ml}$ ) [23]. The methanolic extract showed higher amount of cardiac glycoside content $(4.7 \mu \mathrm{g} / \mathrm{mg})$ as compared to ethanolic extract $(3.7$ $\mu \mathrm{g} / \mathrm{mg}$ ). However, prior investigations only featured preliminary detection of cardiac glycosides but not its quantity in Actinidia fruits.

Total carbohydrate content: Carbohydrates contribute in sweetness, appearance and texture of most of foods. Apart from this each food type has a carbohydrate 'fingerprint', nutrient content, identity and various other factors. Therefore, it is essential to determine carbohydrate content. Total carbohydrate contents (TCC) in EKE and MKE $(100 \mathrm{mg} / \mathrm{ml})$ were calculated using a glucose analytical curve $(10-90 \mu \mathrm{g} / \mathrm{ml})$ based on the UV-Vis signal $(\mathrm{Y}=0.0047 \mathrm{x}$ $\left.+0.438 ; \mathrm{R}^{2}=0.9638\right)$ and phenol-sulphuric acid colorimetric assay. The concentrated sulfuric acid breaks down the polysaccharides, disaccharides and oligosaccharides into monosaccharides. Pentoses are then dehydrated into furfural and hexoses into hydroxymethyl furfural. These compounds imparted yellow-gold colour when they react with phenol. The determination of the TCC of EKE and MKE extracts $(100 \mathrm{mg} / \mathrm{ml})$, expressed as glucose equivalents $(\mu \mathrm{g} /$ $\mathrm{mg}$ ), established higher steroid content (0.24) in methanol extract compared to ethanolic extract (0.22). Deters AM, et al. [43] studied the molar composition of kiwifruit polysaccharide via GC/MS-analysis which identified which identified 9 different types of carbohydrates in A. chinensis: rhamnose, fructose, ribose, arabinose, xylose, mannose, galactose, glucose and uronic acid. 


\section{Antioxidant (DPPH free radical scavenging activity) assay}

DPPH free radical scavenging activity is a sensitive method to analyse the antioxidant activity of a specific compound or plant extract [44]. Determination of A. deliciosa Chev. Fruit antioxidant property was carried out by measuring its ability to scavenge the DPPH radical. DPPH is a free radical that readily undergoes scavenging when in the vicinity of an antioxidant molecule which shows maximum absorbance at $\mathrm{A}_{517}$. The scavenging capacities were reported as percentage reduction of radical (DPPH•). Both alcoholic extracts shared dose-response scavenging abilities and strong percentage reduction. In fact, best scavenging (\%) activity was observed in MKE (72.16\%). On the other hand, EKE showed $61.16 \%$ scavenging activity. The results of the DPPH radical assay strengthened the fact that all of the extracts scavenged massively the radical target species. The observed $\mathrm{IC}_{50}$ (concentration of extracts resulting in 50\% reduction of the DPPH radical) value (Table 2) showed that methanol extract exhibited strongest antioxidant activity $(3.14 \pm 0.153 \mathrm{mg} / \mathrm{ml})$ in comparison with ethanol extract $(4.2 \pm 0.073 \mathrm{mg} / \mathrm{ml})$. The lower the $\mathrm{IC}_{50}$ value, the higher would be the antioxidant activity of the samples. ABTS and FRAP assays were used to evaluate the antioxidant capacity of 5 varieties of Actinidia fruits and this activity varied from 9.40 to 21.36 (ABTS assay) and from 0.87 to 9.22 (FRAP assay) mmoltrolox/100 g of dry weight [37]. Prior investigations highlighted that the ethanolic extracts of $A$. deliciosa fruit to be more potent in reducing free radicals than hexane and diethyl ether extract of A. deliciosa fruit [38].

\section{a-Amylase inhibitory assay}

Human pancreatic a-amylase (E.C. 3.2.1.1) is a key enzyme in digestive system responsible for the breakdown of starch into a mixture of oligosaccharides such as $\alpha$ (1-6), $\alpha$ (1-4) oligoglucans and maltotriose; disaccharides such as maltose and monosaccharides suitable for absorption [45]. The inhibition of $\alpha$-amylase is specifically useful for the treatment of non-insulin-dependent diabetes (Type-2 diabetes) because it will slow down the absorption of glucose $[46,47]$. In the present work, the effects of Actinidiadeliciosa Chev., kiwifruit alcoholic extracts on the catalytic activity of $\alpha$-amylase were evaluated. Extrapolation of extract effectiveness demonstrated inhibition of $\alpha$-amylase was dose-dependent such that MKE had an overall stronger inhibitory effect (85.16\%) than EKE (79.76\%) at a final concentration of $100 \mathrm{mg} / \mathrm{ml}$. The $\mathrm{IC}_{50}$ (Table 3) of MKE $(1.53 \pm 0.158 \mathrm{mg} / \mathrm{ml})$ was significantly lower $(\mathrm{p} \leq 0.05)$ than that of EKE $(2.05 \pm 0.639 \mathrm{mg} / \mathrm{ml})$. Hence, lower $\mathrm{IC}_{50}$ indicates more potent inhibition of enzyme. Kinetic parameters were determined from Lineweaver-Burk plots in presence of two different concentrations of EKE and MKE which showed competitive inhibition of enzyme activity (Figure 1) suggesting $K_{m}$ of a-amylase in absence on extract was $0.722 \mathrm{mg} / \mathrm{mL}$ of starch which was lower than $1.010 \mathrm{mg} / \mathrm{ml}$ and $0.998 \mathrm{mg} / \mathrm{ml}$ of starch for MKE and EKE respectively. Wojdyło A, et al. [37] evaluated $\mathrm{IC}_{50}$ (mg of dried fruit/ $\mathrm{ml}$ ) value of $\alpha$-amylase for five different cultivars of $A$. arguta ranged from 4.13 to 6.62 . Previous studies suggested the strong inhibitory effects on $\alpha$-amylase and free radical scavenging property of kiwifruit extracts and hence their antihyperglycemic and antioxidant capacities $[37,47,48]$. However, findings in a study showed that the flavonoids such ascatechin, quercetin-3-O-glucoside, kaempferol-3-O-rutinoside and kaempferol-3-O-glucoside were found to possess high inhibition activities on $\alpha$-amylase [49].The present, study showed that the active ingredients in the A. deliciosa Chev. Fruit extract competes with the substrate binding in the active site of enzyme. The kiwifruit extract showed potent inhibition of $\alpha$-amylase activity. This result was in accordance with previous studies which showed that extensive inhibition of pancreatic $\alpha$-amylase lead to irregularities in colon due to fermentation of undigested carbohydrates by microbes. Hence, mild $a$-amylase inhibition is desirable [50]. Inhibitory effects of different kiwifruits on $a$-amylase have seldom been investigated. However, kiwifruits exhibited stronger antihyperglycemic activity than pomelo, mandarine, orange, banana, pinapple, pulm, red grapefruit and apple [47].

\section{Starch-agar test}

The starch agar gel diffusion test showed positive results for inhibitory effects of kiwifruit extracts (Figure 2).The antidiabetic effect of kiwifruit has also been demonstrated [51]. Recent study suggested eating kiwifruit during breakfast significantly slowed glucose release into blood stream [52]. Moreover, the phytochemical analysis showed low sugar content in kiwifruit which was in agreement with the previous reports indicating low glycaemic index was beneficial for regulating blood sugar [53,54].

\section{Conclusion}

Kiwifruit is a nutrient-dense food rich in nutrients and low in calories. It is consumed all over the world as salads, juices or as a snack.

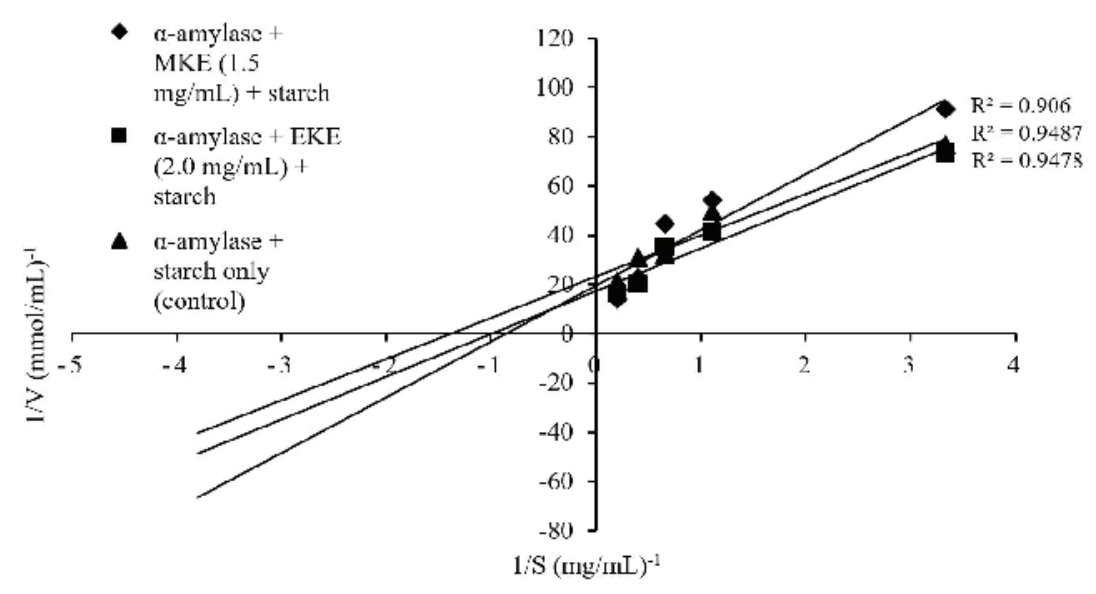

Figure 1: Lineweaver-Burk plot of mode of inhibition of $\alpha$-amylase by EKE and MKE. 

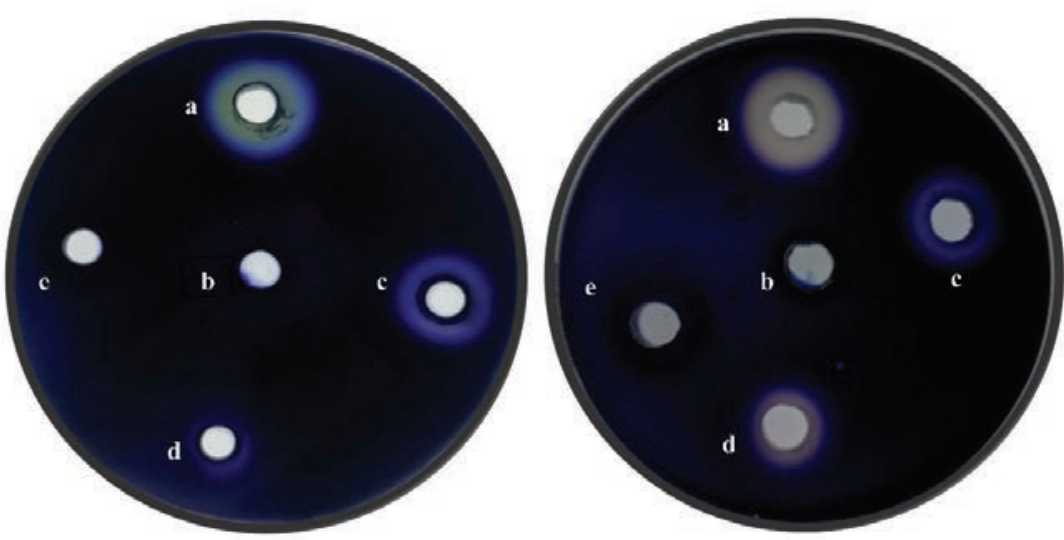

Figure 2: The starch agar plate after treatment of alpha-amylase $(0.5 \mathrm{mg} / \mathrm{mL})$ with MKE and EKE (a) Positive control (b) Negative control (c) $60.0 \mathrm{mg} / \mathrm{ml}$ (d) $80.0 \mathrm{mg} / \mathrm{ml}$ and (e) $100.0 \mathrm{mg} / \mathrm{ml}$.

Table 2: $\mathrm{IC}_{50}$ values of $A$. deliciosa Chev. fruit extracts determined using DPPH assay.

\begin{tabular}{|l|c|}
\hline \multicolumn{1}{|c|}{ Extracts } & IC $_{50}(\mathrm{mg} / \mathrm{mL})$ \\
\hline Methanol & $3.14 \pm 0.153$ \\
\hline Ethanol & $4.2 \pm 0.073$ \\
\hline
\end{tabular}

The values are expressed as mean \pm SEM of triplicate tests $(P \leq 0.05)$.

In present study, phyto-chemical analysis provided an idea about the constituents of Actinidia deliciosa Chev., (Kiwifruit). Later, medicinal nature of the fruit was checked by establishing its antioxidant and anti-hyperglycemic effects. The contribution of kiwifruit to health improvement can be related to its antioxidant capacity. Vitamin C, choline, zeaxanthin and lutein are the major antioxidants which help in removing free radicals from body produced during different metabolic processes. Anti-hyperglycemic compounds are used against diabetes. The study showed that kiwi extract has an excellent antidiabetic potential. Future studies should be based on determining the total antioxidant capacity, content of antioxidants in Actinidia genotypes and antidiabetic potential of fruits of Actinidia since (i) the concentration of antioxidants varies significantly between within their species and subspecies, (ii) to access recommended consumption and marketing of different kiwifruit which could serve as a rich dietary supplement and also help in treatment of diabetes.

\section{Acknowledgments}

This work has been funded by Council for Scientific and Industrial Research, New Delhi, under a CSIR-NET Junior Research Fellowship [File No.09/237(0161)/2017-EMR-1] awarded to one of the authors (VC). The authors are thankful to CSIR, New Delhi as well as DBT, New Delhi for continuous financial support to department of biotechnology, Himachal Pradesh University, Shimla (India).

\section{Conflict of interest}

Authors declare that they have no conflict of interest amongst them or with the parent institute.
Table 3: $\mathrm{IC}_{50}$ values for alpha-amylase inhibitory potential of $A$. deliciosa Chev. extracts.

\begin{tabular}{|l|c|}
\hline \multicolumn{1}{|c|}{ Extracts } & $\mathrm{IC}_{50}(\mathrm{mg} / \mathrm{mL})$ Amylase \\
\hline Methanol & $1.53 \pm 0.091$ \\
\hline Ethanol & $2.05 \pm 0.368$ \\
\hline
\end{tabular}

The values are expressed as mean \pm SEM of triplicate tests $(P \leq 0.05)$.

\section{References}

1. Lahlou EH, Hirai N, Kamo T, Tsuda M, Ohigashi H (2001) Actinidic acid, a new triterpene phytoalexin from unripe kiwi fruit. Biosci Biotechno Biochem 65: 480-483.

2. Cano MP (1991) HPLC separation of chlorophyll and carotenoid pigments of four kiwifruit cultivars. J Agr Food Chem 39: 1786-1791.

3. Wen-Wei FU, Chang-Heng TAN, Lu-Lu LU, Xiang-Xue MENG, HongFeng LUO, et al. (2010) Chemical constituents from the root of Actinidia deliciosa. Chin J Nat Med 8: 247-249.

4. Chinese traditional medicine glossary (1977) Shanghai Science and Technology Publishing Co. 2211.

5. Ferguson AR (1990) The genus Actinidia. In: Warrington IJ, Weston GC, New Zealand Society for Horticultural Science (eds) Kiwifruit: Science and Management. Ray Richards Publication, Auckland, New Zealand.

6. Lim TK (2012) Actinidia deliciosa. In: Edible medicinal and nonmedicinal plants. Springer, Dordrecht 1: 20-29.

7. Duttaroy AK, Jørgensen A (2004) Effects of kiwi fruit consumption on platelet aggregation and plasma lipids in healthy human volunteers. Platelets 15: 287-292.

8. Mirele da Silveira Vasconcelos, Luciana Maia Nogueira de Oliveira, Erika Freitas Mota, Luciana de Siqueira Oliveira, Neuza Felix GomesRochette, et al. (2020) Consumption of rich/enrich phytonutrients food and their relationship with health status of population. In: Seyed Mohammad Nabavi, Ipek Suntar, Davide Barreca, Haroon Khan (eds) Phytonutrients in Food: from Traditional to Rational Usage. Woodhead Publishing 67-101. 
9. Loutfy H Madkour (2020) Antioxidant therapeutic defenses toward redox biology and oxidative stress. In: Nanoparticles induce oxidative and endoplasmic reticulum stresses. Springer Nature 557-613.

10. Tiwari S, Tiwari S, Singh M, Singh A, Prasad M (2017) Generation mechanisms of reactive oxygen species in the plant cell: An overview. In: Vijay Pratap Singh, Samiksha Singh, Durgesh Kumar Tripathi, Sheo Mohan Prasad, Devendra Kumar Chauhan (eds) Reactive Oxygen Species in Plants: Boon Or Bane- Revisiting the Role of ROS, John Wiley \& Sons 2017: 1-22.

11. Abe D, Saito T, Kubo Y, Nakamura Y, Sekiya K (2010) A fraction of unripe kiwi fruit extract regulates adipocyte differentiation and function in 3T3-L1 cells. Biofactors 36: 52-59.

12. Harborne JB (1973) Phytochemical methods: A guide to modern techniques of plant analysis. Springer Science \& Business Media.

13. James O Schreck, William M Loffredo (1994) Qualitative testing for carbohydrates. In: Neidig HA (eds) Chemical Education Resources.

14. Krishnaiah D, Devi T, Bono A, Sarbatly R (2009) Studies on phytochemical constituents of six malaysian medicinal plants. J Med Plants 3: 67-72.

15. Liebermann NC (1885) Über das Oxychinoterpen. Ber dtsch Chem Ges 18: 1803

16. Burchard H (1890) Beitraege zur Kenntnis des Cholesterins. Chem. Zentralbl 61: 25-27.

17. Keller CC (1895) Keller's reagent, Berichte der Deutschen Pharmazeutischen Gesellschaft 5: 277.

18. Kiliani H (1896) Ueber den Nachweis der Digitalis-Glycoside und ihrer Spaltungsprodukte durch eisenhaltige Schwefelsäure. Arch d Pharm 234: 273-277.

19. Wagner $H$ (1993) Pharmazeutischebiologie. $5^{\text {th }}$ Edition, Gustav fisher Vwelag, Stuttgart, Germany.

20. Mahesh AR, Ranganath MK, Harish Kumar DR (2013) Enrichment of flavonoids from the Methanolic extract of Boerhaavia diffusa roots by partitioning technique. Res J Chem Sci 3: 43-47.

21. Stanković MS (2011) Total phenolic content, flavonoid concentration and antioxidant activity of Marrubium peregrinum L. extracts. Kragujevac J Sci 33: 63-72.

22. Patra A, Jha S, Sahu AN (2009) Antidiabetic activity of aqueous extract of Eucalyptus citriodorahook in alloxan induced. Phcog Mag 5: 51-54.

23. Muhammad SA, Abubakar SM (2016) Qualitative and quantitative determination of phytochemicals in aqueous extract of Chrysophyllumalbidum seed kernel. Biosci Biotech Res Asia 13: 1201-1206.

24. Nielsen SS (2010) Phenol-sulfuric acid method for total carbohydrates. In: Nielsen SS (eds) Food Analysis Laboratory Manual, $2^{\text {nd }}$ Edition, Springer Science \& Business Media 47-54.

25. Rajurkar NS, Gaikwad KN, Razavi MS (2012) Evaluation of free radical scavenging activity of Justicia adhatoda: a gamma radiation study. Int J Pharm Pharm Sci 4: 93-96.

26. Chidambara Murthy KN, Jayaprakasha GK, Singh RP (2002) Studies on the antioxidant activity of Pomegranate (Punica granatum) peel and seed extract using in vivo models. J Agri Food Chem 50: 4791-4795.

27. McCue PP, Shetty K (2004) Inhibitory effects of rosmarinic acid extracts on porcine pancreatic amylase in vitro. Asia Pac J Clin Nutr 13: 101-106
28. Ali $\mathrm{H}$, Houghton PJ, Soumyanath A (2006) $\alpha$-Amylase inhibitory activity of some malaysian plants used to treat diabetes with particular reference to Phyllanthus amarus. J Ethnopharmacol 107: 449-455.

29. Vedder EB (1915) Starch agar, a useful culture medium. J Infect Dis 16: 385-388.

30. Yang H, Lee YC, Han KS, Singh H, Yoon M, et al. (2013) Green and gold kiwifruit peel ethanol extracts potentiate pentobarbital-induced sleep in mice via a GABAergic mechanism. Food chem 136: 160-163.

31. Altemimi A, Lakhssassi N, Baharlouei A, Watson DG, Lightfoot DA (2017) Phytochemicals: extraction, isolation and identification of bioactive compounds from plant extracts. Plants (Basel) 6: E42.

32. da Silva RPFF, Rocha Santos TAP, Duarte AC (2016) Supercritical fluid extraction of bioactive compounds. Trend Anal Chem 76: 40-51.

33. Latocha $P$ (2017) The nutritional and health benefits of kiwiberry (Actinidia arguta)-A review. Plant Foods Hum Nutr 72: 325-334.

34. Ichiro Nishiyama, Tetsuo Fukuda, Atsuko Shimohashi, Tadachika Oota (2008) Sugar and organic acid composition in the fruit juice of different Actinidia varieties. Food Sci Technol Res 14: 67-73.

35. Jin DE, Park SK, Park CH, Seung TW, Heo HJ (2014) Nutritional compositions of three traditional Actinidia (Actinidia arguta) cultivars improved in Korea. J Korean Soc Food Sci Nutr 43: 19421947.

36. Dias M, Caleja C, Pereira C, Calhelha RC, Kostic M, et al. (2019) Chemical composition and bioactive properties of byproducts from two different kiwi varieties. Food Res Int 127: 108753.

37. Wojdyło A, Nowicka P, Oszmiański J, Golis T (2017) Phytochemical compounds and biological effects of Actinidia fruits. J Funct Foods 30: 194-202.

38. Fiorentino A, D'Abrosca B, Pacifico S, Mastellone C, Scognamiglio M, et al. (2009) Identification and assessment of antioxidant capacity of phytochemicals from kiwi fruits. J Agric Food Chem 57: 4148-4155.

39. Panche AN, Diwan AD, Chandra SR (2016) Flavonoids: an overview J Nutr Sci 5: e47.

40. Zuo LL, Wang ZY, Fan ZL, Tian SQ, Liu JR (2012) Evaluation of antioxidant and antiproliferative properties of three Actinidia (Actinidia kolomikta, Actinidia arguta, Actinidia chinensis) extracts in vitro. Int J Mol Sci 13: 5506-5518.

41. Sultan A, Raza AR (2015) Steroids: A diverse class of secondary metabolites. Med chem 5: 310-317.

42. Jing $\mathrm{Fu}$, Zhongyuan Wu, Lijuan Zhang (2019) Clinical applications of the naturally occurring or synthetic glycosylated low molecular weight drugs. Prog Mol Biol Transl 163: 487-522.

43. Deters AM, Schröder KR, Hensel A (2005) Kiwifruit (Actinidia chinensis L.) polysaccharides exert stimulating effects on cell proliferation via enhanced growth factor receptors, energy production, and collagen synthesis of human keratinocytes, fibroblasts, and skin equivalents. J Cell Physiol 202: 717-722.

44. Koleva II, van Beek TA, Linssen JP, de Groot A, Evstatieva LN (2002) Screening of plant extracts for antioxidant activity: a comparative study on three testing methods. Phytochem Anal 13: 8-17.

45. Sales PM, Souza PM, Simeoni LA, Silveira D (2012) $\alpha$-Amylase inhibitors: a review of raw material and isolated compounds from plant source. J Pharm Pharm Sci 15: 141-183. 
46. Eichler HG, Korn A, Gasic S, Prison W, Businger J (1984) The effect of new specific $\alpha$-amylase inhibitor on postprandialglucose and insulin excursions in normal subjects and Type 2 (noninsulin dependent) diabetic patients. Diabetologia 26: 278-281.

47. Podsedek A, Majewska I, Redzynia M, Sosnowska D, Koziołkiewicz M (2014) In vitro inhibitory effect on digestive enzymes and antioxidant potential of commonly consumed fruits. J Agri Food Chem 62: 46104617.

48. Hong-Yi Li, Qin Yuan, Yu-Ling Yang, Qiao-Hong Han, Jing-Liu He, et al. (2018) Phenolic profiles, antioxidant capacities, and inhibitory effects on digestive enzymes of different kiwifruits. Molecules 23: 2957.

49. Tan $Y$, Chang SKC, Zhang $Y$ (2017) Comparison of $\alpha$-amylase, $\alpha$-glucosidase and lipase inhibitory activity of the phenolic substances in two black legumes of different genera. Food Chem 214: 259-268.
50. E Apostolidis, Y-I Kwon, K Shetty (2007) Inhibitory potential of herb, fruit, and fungal-enriched cheese against key enzymes linked to type 2 diabetes and hypertension. Innov Food Sci Emerg Technol 8: 46-54.

51. Patel I, Padse O, Ingole Y (2015) Comparative analysis of antioxidant and antidiabetic activity for apple (Malus domestica), banana (Musa paradisiaca) \& kiwi (Actinidia deliciosa). Int J Res Adv Technol 2015: 28-31.

52. Monro J (2016) Kiwifruit-a double agent for glycaemic control and nutrient enhancement. $1^{\text {st }}$ International Symposium on Kiwifruit and Health, Tauranga, New Zealand 17.

53. USDA (2016) National nutrient database for standard reference. Agricultural Research Service, Nutrient Data Laboratory.

54. New Zealand Ministry of Health (2014) New Zealand FOOD files. Version 1 